\title{
Omental patch for closure of a cecal perforation during endoscopic resection of a laterally spreading tumor
}

We present the case of a 65-year-old man with long-standing ulcerative colitis referred to the Digestive Endoscopy Unit of Humanitas Research Hospital (Milan, Italy) to undergo endoscopic removal of a 45-mm granular laterally spreading tumor of the cecum ( $\triangleright$ Fig. 1 ) [1].

The procedure was performed using a standard high definition colonoscope (EG-6000WR; Fujifilm, Tokyo, Japan) under deep sedation and carbon dioxide insufflation. After lesion assessment, including chromoendoscopy with indigo carmine, a decision was made to attempt removal by underwater endoscopic mucosal resection.

After marking the edge of the lesion with snare tip cautery, elevation of the lesion was performed by injection of saline-diluted adrenaline into the submucosal space. Injection was difficult due to the presence of fibrosis. After the initial mucosal resections, the procedure was interrupted after identification of the "target sign" and exposure of omental fat (Sydney's type V) [2,3]. The omental fat was suctioned into the cecum and fixed to the adjacent mucosa with hemoclips. The clips were then pulled together with an endoloop to achieve complete closure of the mural defect by creation of an omental patch ( $\mathbf{F i g . 2 , ~}$ Video 1 ).

A subsequent abdominal computed tomography scan revealed the absence of pneumoperitoneum or fluid collection ( $\mathbf{F i g . 3}$ ). The patient was managed by conservative measures and, because of his clinical history and the incomplete resection of the lesion, a referral was made for elective colectomy. Surgical pathology revealed a tubular adenoma with low grade dysplasia.

Owing to the presence of submucosal fibrosis in patients with ulcerative colitis, therapeutic endoscopy is more challenging and has an increased risk of adverse events. If recognized immediately, endoscopic closure of an iatrogenic perforation could be considered, depending on the size and type of perforation, as well as endoscopist expertise [4]. In the current case, creation of an omental patch provided definitive closure of the cecal perforation. Ultimately, the final clinical outcome depends on the timing and efficacy of intervention.

Endoscopy_UCTN_Code_TTT_1AQ_2A J

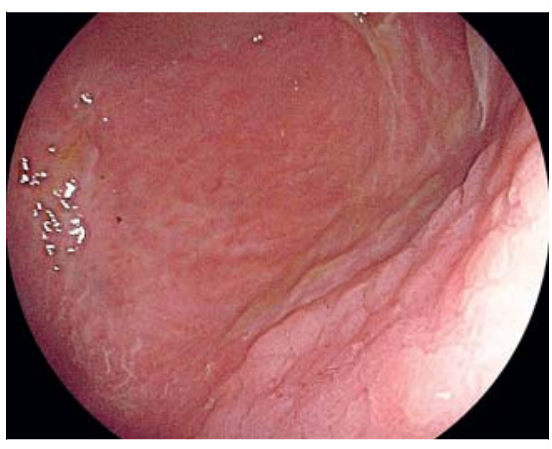

- Fig. 1 Endoscopic image of a granular laterally spreading tumor in the cecum.

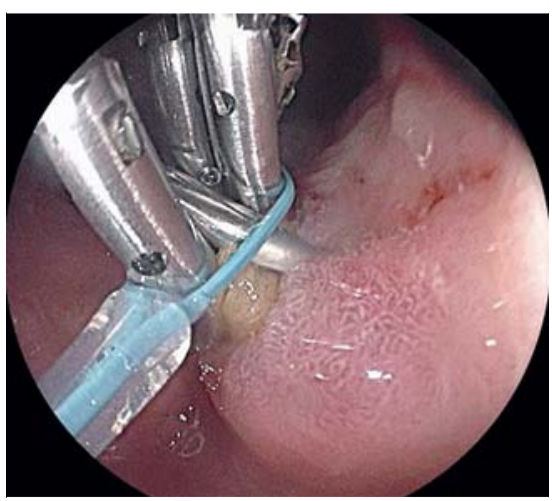

- Fig. 2 Endoscopic closure of the mural defect by creation of an omental patch.

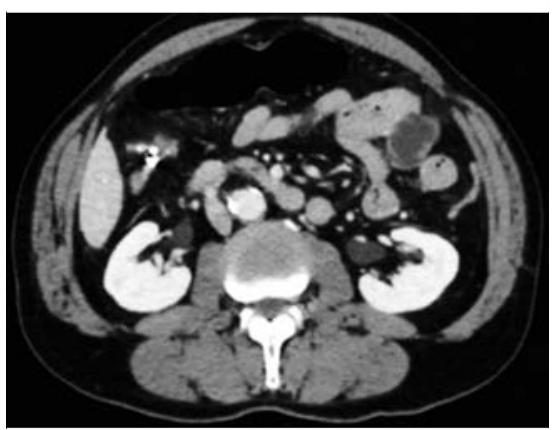

Fig. 3 Computed tomography image confirming absence of pneumoperitoneum or fluid collection.
Video 1 Creation of an omental patch for closure of a perforation during endoscopic resection. 
None

The authors

Piera Alessia Galtieri ${ }^{1}$, Francesco Auriemma ${ }^{2}$, Roberta Maselli', Alessandro Fugazza', Benedetto Mangiavillano², Paul James Belletrutti ${ }^{3}$, Alessandro Repici ${ }^{1,4}$

1 Digestive Endoscopy Unit, Division of Gastroenterology, Humanitas Clinical and Research Center, Rozzano, Milan, Italy

2 Digestive Endoscopy Unit, Humanitas Mater Domini, Castellanza, Italy

3 Section of Gastroenterology and Hepatology, Department of Medicine Cumming School of Medicine, University of Calgary, Calgary, Canada

4 Humanitas Clinical and Research Center, Department of Biomedical Sciences, Humanitas University, Rozzano, Milan, Italy

\section{Piera Alessia Galtieri, MD}

Digestive Endoscopy Unit, Division of Gastroenterology, Humanitas Research Hospital, Via Manzoni 56, 20089 Rozzano, Milano, Italy

piera.galtieri@humanitas.it

\section{References}

[1] Laine L, Kaltenbach T, Barkun A et al. SCENIC international consensus statement on surveillance and management of dysplasia in inflammatory bowel disease. Gastroenterology 2015; 148: 639-651.e28

[2] Swan MP, Bourke M], Moss A et al. The target sign: an endoscopic marker for the resection of the muscularis propria and potential perforation during colonic endoscopic mucosal resection. Gastrointest Endosc 2011; 73 : $79-85$

[3] Burgess NG, Byth K, Bassan MS et al. Deep mural injury and perforation after colonic endoscopic mucosal resection: a new classification and analysis of risk factors. Gut 2017; 66: 1779-1789

[4] Paspatis GA, Dumonceau JM, Barthet M et al. Diagnosis and management of iatrogenic endoscopic perforations: position statement from the European Society of Gastrointestinal Endoscopy (ESGE). Endoscopy 2014; 46: 1-19

\section{Bibliography}

DOI https://doi.org/10.1055/a-0885-9588

Published online: 9.5.2019

Endoscopy 2019; 51: E237-E238

(c) Georg Thieme Verlag KG

Stuttgart · New York

ISSN 0013-726X

\section{ENDOSCOPY E-VIDEOS}

https://eref.thieme.de/e-videos

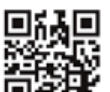

Endoscopy E-Videos is a free access online section, reporting on interesting cases and new

techniques in gastroenterological endoscopy. All papers include a high quality video and all contributions are freely accessible online.

This section has its own submission website at https://mc.manuscriptcentral.com/e-videos 